\title{
HIV risk profile of male street youth involved in survival sex
}

\author{
N Haley, E Roy, P Leclerc, J-F Boudreau, J-F Boivin
}

Sex Transm Infect 2004;80:526-530. doi: 10.1136/sti.2004.010728

See end of article for authors' affiliations

....................

Correspondence to: Dr Nancy Haley, Montreal Public Health Department, Infectious Diseases Unit, 1301 Sherbrooke Street East, Montreal, Quebec, H2L 1M3, Canada; nhaley@santepub-mtl. qc.ca

Accepted for publication 18 June 2004
Objectives: To compare HIV risk factors of male street youth involved in survival sex with those of their never involved peers and to describe the sexual activities of the involved youths.

Methods: From 2001 to 2003, street youth aged 14-23 years were recruited from street youth agencies in Montreal, Canada. Information was collected on sociodemographic characteristics, substance use, and sexual behaviours. Involvement in survival sex was defined as having ever exchanged sex for money, gifts, drugs, shelter, or other needs. Logistic regression was used to identify HIV risk factors associated with involvement in survival sex.

Results: Among the 542 male participants recruited, $27.7 \%$ reported involvement in survival sex. HIV risk factors independently associated with such involvement were injection drug using partners (modulated by length of homelessness), unprotected oral sex with male partners, steroid injection, history of sexual abuse, and drug injection. Among involved youths, $32.0 \%$ had only female clients, $41.3 \%$ only male clients, and $26.7 \%$ had clients of both sexes. Unprotected sexual activities were common with clients. However, even more risks were taken with non-commercial sexual partners.

Conclusions: Male street youth involved in survival sex are at higher risk for HIV than their non-involved peers not only because of their unprotected commercial sexual activities. They have multiple other HIV risks related to non-commercial sexual activities, drug injection, and sexual abuse. All these risks need to be addressed when providing sexual health interventions for this population.
$\mathrm{D}$ isenfranchised youths working and living in the streets, often referred to as "street youth," are increasingly present in many urban cities. In Canada, the United States, and other industrialised nations, street youth refers to individuals aged 25 years or less who have dropped out of school, are without regular employment, and live in precarious conditions, often with little social support from their families or community. These youths lack marketable skills for meeting daily needs and have few opportunities for legitimately supporting themselves. Many of them must rely on illegal activities such as begging, stealing, selling drugs, or trading sex in order to survive. ${ }^{1-3}$ The exact number of street youth is difficult to estimate. They are a transient and difficult to reach population, often fleeing from their families, social service agencies, or the police. In Canada, their number is estimated at between 45000 and $150000 .^{4}$ In the United States, estimates range from 1.3 to 2 million, including approximately 1 million youths who have run away from home or been thrown out. ${ }^{56}$

During the past two decades, numerous studies have documented that street youth are at high risk for many health problems such as sexually transmitted infections, HIV infection, hepatitis B and C, substance misuse, and mental illness leading to increased morbidity and mortality. ${ }^{1-3} 7-14$ Risky sexual and drug use behaviours are frequent among these youths, with many reporting multiple sexual partners, inconsistent condom use, high risk sexual activities, and injection drug use. ${ }^{1811-131516}$ Similarly, involvement in survival sex has been shown to be highly prevalent among

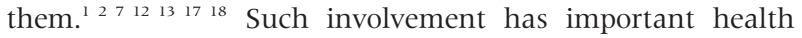
consequences and is often thought to be one of the most damaging repercussions of homelessness for youths. ${ }^{3}$

To what extent being involved in survival sex is associated with more risk factors for HIV infection is unclear. Data on this subject are extremely sparse. A single study comparing HIV risk behaviours of street girls involved and not involved in survival sex has been identified. ${ }^{19}$ In this study, girls involved in survival sex reported a higher rate of injection drug use and engaged in more risky sexual behaviours than their never involved peers. The objectives of this study were to compare the HIV risk factors of male street youth involved in survival sex with those of their never involved peers and to describe the sexual behaviours of those involved.

\section{METHODS}

\section{Study population}

A prospective cohort study of street youth was initiated in Montreal, Canada, in July 2001 to determine the prevalence and incidence of hepatitis C and HIV, and to identify associated risk factors and predictors in this population. This paper is based on the cross sectional data from the first interview questionnaire completed at study entry. Approval was provided by the institutional review board, Faculty of Medicine, McGill University.

Entry criteria are based on those of the first Montreal street youth cohort ${ }^{20}$; they were defined in collaboration with street youth agencies to capture a broad spectrum of street youth. These criteria are being "street active," aged 14-23 years, English or French speaking, and able to provide informed consent and to complete an interviewer administered questionnaire. Youths are considered "street active" if they have, in the last year, either regularly used the services of street youth agencies, or been without a place to sleep more than once. These community agencies are drop-in centres, shelters, or outreach vans; they offered a range of services such as food, short term housing, and social and preventive healthcare services.

\section{Recruitment}

Study interviewers recruit participants during regular visits to all major street youth agencies in Montreal. Visit frequency, based on the number of youth served by each agency, ranges from three times a week to once a month. Eligible youths 
Table 1 Comparison of personal characteristics of male street youth involved and never involved in survival sex

\begin{tabular}{llll}
\hline & $\begin{array}{l}\text { Involved } \\
\text { (n=150) }\end{array}$ & $\begin{array}{l}\text { Never involved } \\
\text { (n=392) }\end{array}$ & p Value \\
\hline Mean age (years) & 21.1 & 20.5 & 0.003 \\
Canadian born & $95.3 \%$ & $89.5 \%$ & 0.034 \\
French speaking & $91.3 \%$ & $86.5 \%$ & 0.122 \\
Comfortable family socioeconomic status* $^{*}$ & $68.8 \% \dagger$ & $59.8 \% \ddagger$ & 0.061 \\
Homeless $\geqslant 6$ months & $80.0 \%$ & $54.5 \% \S$ & $<0.001$ \\
\hline
\end{tabular}

*Two upper levels of four point scale combined.

†9 missing.

¥11 missing.

$\S 1$ missing.

receive an appointment for their first interview at the study office located in the downtown area where most street youth hang out. After completing the interview, youths receive a financial compensation of \$C30 for their participation.

\section{Measurements}

The study questionnaire is administered by an interviewer; it covers mainly sociodemographic characteristics, alcohol and drug use, and sexual behaviours. Lifetime characteristics and behaviours from the first interview were used to compare the HIV risk factors of male street youth ever involved in survival sex to the risks of their never involved peers, and to describe sexual activities of those involved. Participants were considered involved in survival sex if they answered yes to the question "In your life, have you ever received money, gifts, a place to sleep, or something else in exchange for sexual activities? If yes, was it with women; was it with men?" Admissible youths rarely refused to participate. In a related study we have conducted in the same population, we estimated that approximately $12 \%$ of offers to participate were declined..$^{20}$

For the comparative analysis, the personal characteristics studied were age, country of birth, language, perceived family socioeconomic status (measured on a four point scale; the two upper levels combined were defined as comfortable socioeconomic status), and total duration of homelessness (combining all episodes when the youths had to sleep in such places as outside, in a shelter, at a friend or relative's place because they had nowhere else to go).

The sexual behaviours studied were unprotected oral, vaginal, and anal sex with non-commercial partners of both sexes (all studied separately). Also included were reported sexual activities with a person who had injected drugs (an HIV prevalence of $18 \%$ has been observed among injection drug users in Montreal $^{21}$ ) and sexual activities with an HIV infected person. As well, youths were asked about a history of sexual abuse (excluding incest).

Other HIV risk factors studied were tattooing, body piercing (piercing elsewhere than ears), scarification, steroid injection, drug injection, problematic alcohol use (measured by a CAGE score $\geqslant 3),{ }^{22}$ and number of types of drugs consumed (types of drugs were as follows: cannabis, hallucinogens (PCP, LSD, or mushroom), cocaine/crack, heroin, speedball (mix of cocaine and heroin), solvents, amphetamines, medications taken for non-medical reasons, and other drugs).

The sexual activities of youths involved in survival sex considered in the descriptive analysis were vaginal and anal penetrations and oral sex with female and male clients and non-commercial partners. Proportions of youths who did not consistently used condom among those reporting each activity were also studied.

Participants also provided a blood sample for HIV and hepatitis $\mathrm{C}$ antibody testing.

Table 2 Comparison of lifetime HIV risk factors of male street youth involved and never involved in survival sex

\begin{tabular}{|c|c|c|c|}
\hline & $\begin{array}{l}\text { Involved } \\
(n=150)\end{array}$ & $\begin{array}{l}\text { Never involved } \\
(n=392)\end{array}$ & p Value \\
\hline \multicolumn{4}{|l|}{ Sexual HIV risk factors } \\
\hline Unprotected vaginal penetration & $87.3 \%$ & $78.8 \% *$ & 0.023 \\
\hline Unprotected anal penetration & $36.7 \%$ & $20.0 \% \dagger$ & $<0.001$ \\
\hline Unprotected oral sex & $91.3 \%$ & $89.0 \% *$ & 0.426 \\
\hline \multicolumn{4}{|l|}{ With male non-commercial partners: } \\
\hline Unprotected anal penetration & $8.7 \%{ }^{*}$ & $2.0 \%$ & 0.001 \\
\hline Unprotected oral sex & $29.3 \%$ & $6.4 \%$ & $<0.001$ \\
\hline \multicolumn{4}{|l|}{ High risk sexual partners: } \\
\hline Sexual partners injecting drugs & $64.7 \%$ & $32.5 \% *$ & $<0.001$ \\
\hline HIV positive sexual partners & $10.7 \%$ & $3.3 \%^{*}$ & 0.001 \\
\hline History of sexual abuse & $31.8 \% \dagger$ & $10.1 \% \ddagger$ & $<0.001$ \\
\hline \multicolumn{4}{|l|}{ Other HIV risk factors } \\
\hline Tattooing & $57.3 \%$ & $48.5 \%$ & 0.065 \\
\hline Body piercing & $53.3 \%$ & $40.6 \%$ & 0.007 \\
\hline Scarification & $24.7 \%$ & $16.8 \%$ & 0.038 \\
\hline Steroid injection & $6.7 \%$ & $1.0 \%$ & 0.001 \\
\hline Drug injection & $66.0 \%$ & $33.4 \%$ & $<0.001$ \\
\hline Problematic alcohol use & $32.4 \% \dagger$ & $26.1 \% *$ & 0.142 \\
\hline Number of types of drugs consumed (mean) & 5.8 & 4.7 & $<0.001$ \\
\hline
\end{tabular}


Table 3 Multivariate logistic regression model: HIV risk factors independently associated with involvement in survival sex among male street youth $(n=533)$

\begin{tabular}{lll}
\hline & AOR* & $95 \% \mathbf{C l}$ \\
\hline Sexual partners injecting drugs & & \\
$\quad$ If homeless $<6$ months & 6.4 & 2.6 to 16.1 \\
If homeless $\geqslant 6$ months & 1.5 & 0.9 to 2.6 \\
Unprotected oral sex with male non-commercial partner & 5.1 & 2.8 to 9.4 \\
Steroid injection & 3.9 & 1.0 to 15.6 \\
History of sexual abuse & 3.6 & 2.1 to 6.1 \\
Drug injection & 2.4 & 1.4 to 3.8 \\
\hline *Adjusted odds ratio. & & \\
\hline
\end{tabular}

\section{Statistical methods}

Prevalence rate of survival sex and 95\% exact binomial confidence intervals were calculated. Personal characteristics and HIV risk factors of youths involved in survival sex were compared with those of the never involved using Pearson $\chi^{2}$ or Fisher's exact tests for dichotomous variables and Student's $t$ test for continuous variables. Forward procedure on the significant correlates of survival sex $(p<0.05)$ was used to build a multivariate logistic regression model. Personal characteristics were included in the forward procedure because of their potential confounding effect. Interactions between the selected personal characteristics and HIV risk factors were also tested.

\section{RESULTS}

As of 30 November 2003, 794 youths were recruited in the study, including 542 males (68.3\%). Among them, 150 $(27.7 \%)$ were ever involved in survival sex $(95 \%$ confidence interval: 23.9 to 31.6). The global HIV prevalence rate observed among street males was $0.8 \%(2.1 \%$ among those ever involved in survival sex, $0.3 \%$ among those never involved).

\section{Comparison of personal characteristics and HIV risk factors of involved and never involved youths}

As shown in table 1, youths involved and never involved in survival sex differed significantly in terms of some personal characteristics. Involved males were slightly older, more of them were Canadian born, and more of them had been homeless for 6 months or more in their life.

The HIV risk factors are shown in table 2. Youths involved in survival sex were more likely to report all types of risky sexual activities, sexual partners who inject drugs, and a history of sexual abuse than their never involved peers; all differences were statistically significant except for unprotected oral sex with females. Body piercing, scarification, steroid injection, and drug injection were also significantly more frequent among youths involved in survival sex. Finally, involved youth reported having used a greater variety of drugs.

The final multivariate model is shown in table 3. Sexual partners reporting drug injection (modulated by the length of homelessness), unprotected oral sex with non-commercial male partners, steroid injection, history of sexual abuse, and drug injection were identified as independent correlates of involvement in survival sex when taking into account the confounding effect of duration of homelessness. Each of these variables thus differentiates youths ever and never involved in survival sex, even after the remaining variables in the model are taken into account.

\section{Description of sexual activities of youths involved in survival sex}

Participants involved in survival sex can be divided into three groups according to the sex of their clients: $32.0 \%(n=48)$ had only female clients, $41.3 \%(n=62)$ had only male clients, and $26.7 \%(n=40)$ reported clients of both sexes. Youths with female clients reported a median of two such clients in their life (range 1-75); for those with male clients, the median was 10 (range 1-1500).

As shown in table 4, vaginal penetration and oral sex were the activities reported most often with female clients. Among those reporting vaginal or anal penetrations, approximately $40 \%$ reported non-consistent condom use; this proportion doubled for oral sex. With male clients, oral sex was three times more frequent than anal penetration. A quarter of youths reporting anal sex had unprotected penetration and for oral sex, this proportion reached $71 \%$.

Participants also had diverse profiles based on the sex of their non-commercial partners: $0.7 \%(\mathrm{n}=1)$ had no such partners, $0.7 \%(\mathrm{n}=1)$ only had one male partner, $64.0 \%$ $(\mathrm{n}=96)$ only female partners, and $37.7 \%(\mathrm{n}=37)$ had both

Table 4 Lifetime sexual behaviours of the 150 male street youth involved in survival sex with their clients and non-commercial partners

\begin{tabular}{|c|c|c|c|c|c|c|}
\hline & \multicolumn{2}{|c|}{ Oral sex } & \multicolumn{2}{|c|}{ Vaginal penetration } & \multicolumn{2}{|c|}{ Anal penetration } \\
\hline & No & $\%$ & No & $\%$ & No & $\%$ \\
\hline \multicolumn{7}{|l|}{ With clients } \\
\hline Ever with a female* & 77 & $52.0 \%$ & 81 & $54.7 \%$ & 24 & $16.2 \%$ \\
\hline Ever unprotected $\ddagger$ & 66 & $85.7 \%$ & 35 & $43.2 \%$ & 10 & $41.7 \%$ \\
\hline Ever with a malet & 94 & $63.1 \%$ & - & - & 30 & $20.1 \%$ \\
\hline Ever unprotected $\ddagger$ & 67 & $71.3 \%$ & - & - & 8 & $26.7 \%$ \\
\hline \multicolumn{7}{|l|}{ With non-commercial partners } \\
\hline Ever with a female & 141 & $94.0 \%$ & 146 & $97.3 \%$ & 76 & $50.7 \%$ \\
\hline Ever unprotected $\ddagger$ & 137 & $97.2 \%$ & 131 & $89.7 \%$ & 55 & $72.4 \%$ \\
\hline Ever with a male & 52 & $34.7 \%$ & - & - & 34 & $22.8 \%$ \\
\hline Ever unprotected $\ddagger$ & 44 & $84.6 \%$ & - & - & 13 & $38.2 \% \dagger$ \\
\hline
\end{tabular}


male and female partners. Youths with female partners $(n=148)$ reported a median of 20 female partners in their lifetime (range 1-700); for youths with male partners $(n=53)$, the median number of male partners was three (range 1-1500).

As shown in table 4, a greater proportion of involved youths reported all types of sexual activities with their noncommercial female partners than with their female clients. Concerning male partners, a greater proportion of youths reported oral sex with clients than with non-commercial partners; for anal penetration, proportions were similar in both cases. With both males and females, and for all types of activities, proportions reporting unprotected sex were always higher with non-commercial partners than with clients.

\section{DISCUSSION}

Survival sex is a common occurrence among male street youth in Montreal with more than a quarter reporting involvement. This rate is comparable with those reported in other studies in industrialised countries where estimates of involvement in the sex trade among male street youth range from $10 \%$ to $50 \%$, depending on the definition and period of reference used..$^{1-3} 7131718$ Much of the variation in these estimates may be due to the definitions chosen for sex trade involvement. Some investigators used a narrow definition that includes only the exchange of sexual activities for money, while others used a broader definition that also included trading sexual activities for food, shelter, protection, drugs, or other needs.

This is the first study to compare the HIV risk factors of male street youth involved in survival sex with those of their never involved peers. While both groups of youths have multiple risk behaviours for HIV transmission, youths involved in survival sex are at even greater risk than their peers, not only because of their commercial sexual activities but also for all HIV risk factors studied. The independent HIV risk factor with the strongest association with involvement in survival sex was having had sexual partners who inject drugs. The effect of that variable is especially important for youths who had been homeless for a shorter period. Among youths new to the street, those who had sexual partners injecting drugs are more likely to be involved in survival sex. Among those who have been on the street longer, this HIV risk variable ceases to differentiate the two groups. This suggests that as the youths pass more time on the streets, their chance of having sexual partners who inject drugs increases even if they are not involved in survival sex. This is plausible given the high risk environment typical of living on the streets.

Unprotected oral sex with male partners was also found to be independently associated with involvement in survival sex. The per contact risk of HIV transmission due to unprotected oral sex has been considered low compared to other sexual activities. ${ }^{23}$ However, the high prevalence of this practice may result in a significant probability of transmission. This is particularly true since the risk of transmission may be increased if there are oral lesions, such as buccal ulcers or gingivitis, two conditions that are common among youths living on the streets. ${ }^{24}$ As well, since many street youth report high risk partners, their unprotected oral sexual activities may represent a potential for HIV transmission.

The injection of steroids was found to be another HIV risk factor that significantly differentiated youths involved in survival sex from their peers. The reasons for this remain obscure. In a study among adolescents, use of steroids was significantly associated with polydrug use. ${ }^{25}$ Thus, in our sample, the higher risk of steroid injection among youths involved may be a reflection of their polydrug consumption. Another possible explanation could be that youths soliciting clients may be more likely to use steroids as a body enhancer or to increase libido. ${ }^{26}$ Whatever the reason, the use of steroids has been associated with riskier sexual activities and sharing of injection materials..$^{27}$

Sexual abuse is an HIV risk factor independently associated with involvement in survival sex. Youths with a history of sexual abuse have odds four times higher of being involved in survival sex. This may be a reflection of the violent environment in which they are working. Regardless of the circumstances and timing of the sexual aggression, on which we have no details, it represents an important HIV risk factor for two reasons. Firstly, it may in itself represent a risk of HIV transmission as a result of the often traumatic and unprotected nature of the act. Secondly, it may also put the youths at increased risk of engaging in unsafe sex because of the associated short and long term psychological trauma which may lower self esteem and, subsequently, decrease self protective behaviours.

The fact that almost one third of these young men have experienced sexual abuse is of concern. Early detection of youths having been sexually abused should be a health priority and it is important that medical as well as psychological post-trauma care be available for these youths. ${ }^{29}$ In addition, the link between sexual victimisation, sexual and drug risk behaviours, and risk of homelessness needs to be clarified.

Finally, several authors have reported problematic drug misuse among street youth. ${ }^{1-3} 8131618$ Our data show that drug misuse is even worse among males involved in survival sex than among those not involved. This association between drug injection and involvement in survival sex has been reported in other populations. ${ }^{18} 1930$ This finding is of major concern in a city such as Montreal where the HIV epidemic is driven by injection drug use and, to a lesser extent, by unsafe sexual practices among homosexual men.

Sexual behaviours of males involved in survival sex Male street youth involved in survival sex reported a variety of experiences, with $32 \%$ reporting only female clients, $41 \%$ only male clients, and $27 \%$ reporting clients of both sexes. The diversity of commercial sex activities reported by the involved youths was a surprise, especially the number reporting only female clients. This finding demonstrates that youths involved in survival sex are a very heterogeneous group. While oral sex is the sexual practice reported most often in the context of survival sex, a certain proportion of involved youths also reported unprotected vaginal and anal sex with clients. Although HIV risk behaviours related to commercial sex are present, a greater proportion of involved youths reported unprotected relations with their noncommercial partners than with their clients. Similar findings have been reported by other researchers who noted that sex workers use condoms more readily with clients than with non-work partners. ${ }^{18} 3031$ Consequently, sexual health promotion messages need to be individualised according to type of client and type of sexual practices. Ways to decrease risk taking with non-commercial partners merit particular attention.

\section{Limitations}

Several factors need to be taken into consideration when interpreting the data. Firstly, the youths were classified as being involved in survival sex based on self reported data. Therefore, we may have misclassified youths involved if some of them found it difficult to admit this type of activity. The same was true for all studied behaviours, all self reported. We have attempted to minimise this bias by assuring participants of confidentiality. Secondly, part of the observed association between IDU partners and survival sex might be explained by the fact that some sexual partners injecting drugs may have 
been clients. Finally, since the definition used for survival sex was broad, our findings may not be generalisable to those youths involved in the sex trade in other contexts than the street, such as in escort services.

\section{CONCLUSION}

The risk for HIV among male street youth involved in survival sex is present in many spheres of their lives. While they do engage in unprotected sexual activities with clients, their risks for sexual transmission of HIV appear to also be related to unprotected sex with their non-commercial partners. A risk of HIV transmission is also present through injection drug use, steroid injection, and sexual abuse. The sexual health needs of these youth require evaluation and counselling on these different aspects of their lives, beyond their involvement in survival sex. Comprehensive health services are needed for these youths to prevent new HIV infections. These services should be multidisciplinary, with medical, social, and psychological experts working together to provide mental health and addiction services. Through these services, there may be opportunities to link youths to social and educational resources that will offer them possibilities to find alternative ways of surviving and, eventually, increase their chances of leaving the streets.

Finally, increased efforts to prevent homelessness are required. Supervised and subsidised housing for youths with mental health problems and addiction services for adolescents and their families suffering from drug misuse are urgently needed. As well, adapted educational and work programmes need to be offered to youths having difficulty in the mainstream educational system. Living on the streets causes great mental and physical harm and we have a social responsibility to develop new opportunities for youths that will give them alternatives to the streets.

\section{ACKNOWLEDGEMENTS}

The authors wish to thank the youths who participated in this study as well as the 20 collaborating street youth community organisations. This study was made possible through the contributions of the members of the research team: coordinator, interviewers, nurses, secretaries, and data entry clerk. This study was financially supported by the Quebec Ministry of Health, the Fonds de recherche en santé du Québec, Supporting Communities Partnership Initiative, Human Resources Development Canada, Health Canada, and the Direction de santé publique de Montréal.

\section{CONTRIBUTORS}

The five co-authors are responsible for this paper and have participated in the concept and design of the study; they have been actively involved in the review and interpretation of various areas of the literature and have analysed and interpreted the results; all authors have also contributed to the writing of the final manuscript.

\section{Authors' affiliations}

N Haley, E Roy, P Leclerc, J-F Boudreau, Montreal Public Health Department, Infectious Diseases Unit, Quebec, Canada N Haley, E Roy, J-F Boivin, McGill University, Montreal, Quebec, Canada

\section{REFERENCES}

1 Kipke MD, O'Connor S, Palmer R, et al. Street youth in Los Angeles. Profile of a group at high-risk for human immunodeficiency virus infection. Arch Pediatr Adolesc Med 1995; 149:513-19.

$2 \mathrm{Kral} \mathrm{AH}$, Molnar BE, Booth RE, et al. Prevalence of sexual risk behaviour and substance use among runaway and homeless adolescents in San Francisco, Denver and New York City. Int J STD AIDS 1997;8:109-17.

3 Greene JM, Ennett ST, Ringwalt CL. Prevalence and correlates of survival sex among runaway and homeless youth. Am J Public Health 1999;89:1406-9.

4 Canadian Paediatric Society. Bringing street youth out of the shadows. CPS News 1998;(May/June):5-6.

5 Ringwalt CL, Greene JM, Robertson M, et al. The prevalence of homelessness among adolescents in the United States. Am J Public Health 1998;88:1325-9.

6 National Runaway Switchboard. Consulted 3 March 2004 on

www.nrscrisis.org

7 Anderson JE, Freese TE, Pennbridge JN. Sexual risk behavior and condom use among street youth in Hollywood. Fam Plann Perspect 1994;26:22-5.

8 Bailey SL, Camlin CS, Ennett ST. Substance use and risky sexual behavior among homeless and runaway youth. J Adolesc Health 1998;23:378-88.

9 Roy $\mathrm{E}$, Haley $N$, Lemire $N$, et al. Hepatitis $B$ virus infection among street youths in Montreal. Can Med Ass J 1999;161:689-93.

10 Roy E, Haley N, Leclerc $P$, et al. Risk factors for hepatitis $C$ virus infection among street youths. Can Med Ass J 2001;165:557-60.

11 Pfeifer RW, Oliver J. A study of HIV seroprevalence in a group of homeless youth in Hollywood, California. J Adolesc Health 1997;20:339-42.

12 Stricof RL, Kennedy JT, Nattell TC, et al. HIV seroprevalence in a facility for runaway and homeless adolescents. Am J Public Health 1991;81(Suppl):50-3.

13 Roy $E$, Haley N, Leclerc $P$, et al. Prevalence of HIV infection and risk behaviours among Montreal street youth. Int J STD AIDS 2000;1 1:241-7.

14 Roy E, Boivin JF, Haley N, et al. Mortality among street youth. Lancet 1998;352:32.

15 Ennett ST, Federman EB, Bailey SL, et al. HIV-risk behaviors associated with homelessness characteristics in youth. J Adolesc Health 1999;25:344-53.

16 Yates GL, Mackenzie RG, Pennbridge J, et al. A risk profile comparison of homeless youth involved in prostitution and homeless youth not involved. $J$ Adolesc Health 1991; 12:545-8.

17 Pennbridge JN, Freese TE, MacKenzie RG. High-risk behaviors among male street youth in Hollywood, California. AIDS Educ Prev 1992;(Supp 1):24-33.

18 Howard J. Taking a chance on love: risk behaviour of Sydney street youth. Paediatr Child Health 1993;29(Suppl 1):S60-5.

19 Weber AE, Boivin JF, Blais L, et al. HIV risk profile and prostitution among female street youths. J Urban Health 2002;79:525-35.

20 Roy $\mathrm{E}$, Haley N, Leclerc $\mathrm{P}$, et al. Drug injection among street youths in Montreal: predictors of initiation. J Urban Health 2003;80:92-105.

21 Hankins C, Alary M, Parent R, et al and the SurvUDI Working Group. Continuing HIV transmission among injection drug users in eastern central Canada: the SurvUDI Study, 1995 to 2000. J AIDS 2002;30:514-21.

22 Ewing JA. Detecting alcoholism: the CAGE questionnaire. JAMA 1984;252:1905-7.

23 Vittinghoff E, Douglas J, Judson F, et al. Per-contact risk of human immunodeficiency virus transmission between male sexual partners. Am J Epidemiol 1999;150:306-11.

24 Feldmann J, Middleman AB. Homeless adolescents: common clinical concerns. Sem Pediatr Infect Dis 2003;14:6-11.

25 Durant RH, Ashworth CS, Newman C, et al. Stability of the relationships between anabolic steroid use and multiple substance use among adolescents. J Adolesc Health 1995; 15:111-6.

26 Midgley SJ, Heather N, Best D, et al. Risk behaviours for HIV and hepatitis infection among anabolic-androgenic steroid users. AIDS Care 2000;12:163-70.

27 Bolding G, Sherr L, Maguire $M$, et al. HIV risk behaviours among gay men who use anabolic steroids. Addiction 1999;94:1829-35.

28 Delalande CL, Aitken CK, Mercuri P, et al. Risky practices among people who inject steroids. Med J Aust 1998; 169:62.

29 Deisher R, Robinson G, Boyer D. The adolescent female and male prostitute. Pediatr Ann 1982;11:819-25.

30 Estcourt CS, Marks C, Rohrsheim R, et al. HIV, sexually transmitted infections, and risk behaviours in male commercial sex workers in Sydney. Sex Transm Infect 2000;76:294-8.

31 Spittal PM, Bruneau J, Craib KJ, et al. Surviving the sex trade: a comparison of HIV risk behaviours among street-involved women in two Canadian cities who inject drugs. AIDS Care 2003;15:187-95. 